\title{
Ignition of single coal particle in a hot furnace under normal- and micro-gravity condition
}

\author{
Mingming Zhu ${ }^{\text {a }}$, Hai Zhang ${ }^{\mathrm{a}, *}$, Gentu Tang ${ }^{\mathrm{a}}$, Qing Liu ${ }^{\mathrm{a}}$, Junfu Lu ${ }^{\mathrm{a}}$, \\ Guangxi Yue $^{\mathrm{a}}$, Shuangfeng Wang ${ }^{\mathrm{b}, 1}$, Shixin Wan ${ }^{\mathrm{b}}$ \\ ${ }^{a}$ Key Laboratory for Thermal Science and Power Engineering of Ministry Education, Department of Thermal Engineering, \\ Tsinghua University, Haidian District, Beijing 100084, China \\ ${ }^{\mathrm{b}}$ National Microgravity Laboratory, Institute of Mechanics, Chinese Academy of Science, China
}

\begin{abstract}
An experimental study on ignition and combustion of single particles was conducted at normal gravity (1-g) and microgravity $(\mu-\mathrm{g})$ for three high volatile coals with initial diameter of 1.5 and $2.0 \mathrm{~mm}$, respectively. The non-intrusive twin-color pyrometry method was used to retrieve the surface temperature of the coal particle through processing the images taken by a color CCD camera. At the same time, a mathematical model considering thermal conduction inside the coal particle was developed to simulate the ignition process.

Both experiments and modeling found that ignition occurred homogeneously at the beginning and then heterogeneously for the testing coal particles burning at $\mu$-g. Experimental results confirmed that ignition temperature decreased with increasing volatile content and increasing particle size. However, contradicted to previous studies, this study found that for a given coal with certain particle size, ignition temperature was about $50-80 \mathrm{~K}$ lower at $\mu$-g than that at $1-\mathrm{g}$.

The model predictions agreed well with the $\mu$-g experimental data on ignition temperature. The criterion that the temperature gradient in the space away from the particle surface equaled to zero was validated to determine the commence of homogeneous ignition. Thermal conduction inside the particle could have a noticeable effect for determining the ignition temperature. With the consideration of thermal conduction, the critical size for the phase transient from homogeneous to heterogeneous is about $700 \mu \mathrm{m}$ at ambient temperature $1500 \mathrm{~K}$ and oxygen concentration 0.23 .

(C) 2009 The Combustion Institute. Published by Elsevier Inc. All rights reserved.
\end{abstract}

Keywords: Ignition; Single coal particle; Microgravity; Ignition temperature; Buoyancy effect

\section{Introduction}

Understating the ignition process of coal particles is important for burner and combustor

\footnotetext{
${ }^{*}$ Corresponding author. Fax: +861062788523 .

E-mail addresses: haizhang@tsinghua.edu.cn Zhang), sfwang@imech.ac.cn (S. Wang).

1 Fax: +861062579173.
}

design, and unwanted-fire prevention. For simplification, single-particle studies were often taken [e.g., 1-11]. Some of them experimentally obtained a large amount data on the ignition temperature and ignition time, and some of them developed ignition models. However, most of the experimental data still can not be deemed as the instinct ones, upon which mathematical models can be well validated. One of the important 
reasons is that nearly all corresponding experiments were conducted on the earth, at normal gravity (1-g). Under such circumstances, the ignition process was subjected to the influence of buoyancy-induced natural convection, i.e., buoyancy effect. Due to the large temperature difference, there was large density difference between the burning volatile matter and ambient gas. It was found that natural convection can sweep the surrounding volatile cloud away, noticeably affecting the ignition temperature and time $[9,10]$. And the buoyancy effect is expected to more significant for larger size particles, as the Grashof Number $G r\left(g \rho^{2} \beta \Delta T d_{p}^{3} / \mu^{2}\right)$ increases [10].

Microgravity $(\mu-g)$ experiments are usually desired in minimizing the buoyancy effect. Pioneering study conducted by Gieras et al. [12] in 1980 s, assessed flame transition from burning to unburnt particles at $\mu-g$. However, no data of ignition temperature and ignition time, neither comparison with $1-\mathrm{g}$ were reported. In the mid 1990s, Katalambula et al. [10] conducted more deliberated $\mu-g$ experiments, studying the ignition temperature, time, volatile matter released with different particle size and coal type at both $\mu-g$ and 1-g. In the later 1990s, using the same experimental apparatus, Wendt et al. [13] conducted some $\mu-g$ experiments on the variation of ignition delay time with particle shape. Based on the experiments, noticeable differences were found on the ignition behaviors of coal particles burning at $\mu-g$ and those at $1-g$.

However, there were some controversies between existing experimental data and theory analysis. For example, Katalambula et al. [10] found that the ignition temperature was higher and ignition time was longer at $\mu-g$ than those at $1-\mathrm{g}$. They attributed the differences to the weaker diffusion transport at $\mu-g$. However, just as discussed by themselves [10,11], the concentration of surrounding volatile cloud, which was regarded as a crucial factor for ignition was to be increased at $\mu$-g rather than to be decreased at $1-g$ due to the sweeping of natural convection. If so, the ignition temperature should decrease and ignition time should be shorter at $\mu-\mathrm{g}$.

The experimental setup and measurement method used in previous studies conducted by Katalambula et al. [e.g., 10,11] were also questionable. In their experiments, the coal particles were heated up by the spot heaters, controlled at a desired heating rate. However, the surrounding oxidizer, as well as the evolved volatile cloud was at a relatively low temperature. This setting differed from the hot furnace used in conventional boilers. Furthermore, the method used to measure the surface temperature with a set of fine thermocouples coiling around the particle introduced a few drawbacks. First, the thermocouples' reading was questionable to well represent the particle surface temperature, since the bean of the thermo- couples located away from the particle, in the gas phase environment. Second, the thermocouples were of $\mathrm{Pt} / \mathrm{Pt}-\mathrm{Rh}$ type and could be an effective catalyst for the homogeneous ignition reaction. Third, the thermocouples influenced the flow field, affecting data obtained at both $\mu-\mathrm{g}$ and $1-\mathrm{g}$.

Modeling of single particle ignition and combustion has been rather more active and extensive, compared with the costly $\mu-g$ experiments. Various models of coal ignition have been developed [e.g., 1-6,11,14]. However, nearly all of them neglected the influence of natural convection while the results were directly compared with experimental data obtained at $1-\mathrm{g}$ in the presence of natural convection. Obviously, this kind of manipulation, though convenient, could induce noticeable discrepancy, especially for large coal particles with diameter larger than $1 \mathrm{~mm}[5,8]$. One important reason to cause this mismatch was due to lack of experimental data at $\mu$-g. As introduced, experimental data, even with questionable accuracy were only available after 1990s. Besides, in all existing models, no thermal conduction in the coal particle has been considered.

The main objective of this work is divided in two manifolds. One is to obtain more instinct ignition data of single coal particles with different diameter and coal type, by conducting experiments at $\mu-g$ using a hot furnace heating system. The data will also be compared with those obtained at $1-\mathrm{g}$. The other is to develop a mathematic model that considers the conductive heat transfer inside the coal particle and use the model to predict ignition temperature with comparison of the $\mu-g$ experimental data. The conduction effect inside the coal particle is to be assessed.

\section{Experimental approach}

The $\mu-g$ experiments were conducted in the $3.5 \mathrm{~s}$ drop tower recently built in the Chinese National Microgravity Laboratory (NMLC), Beijing, China. The experimental system, schematically shown in Fig. 1, was mainly consisted of a power supply, a particle feeder, a hot furnace, a temperature controller and an image and data recording device. The temperature of the furnace was maintained at a desire temperature $1123 \mathrm{~K}$.

Two bituminous coals and one lignite coal, namely, Datong bituminous (DTB), Sandaocha bituminous (SDB) and Huolinhe lignite (HLL), were used, and their proximate and ultimate analyses were given in Table 1. The diameters of the particles were of 1.5 and $2.0 \mathrm{~mm}$, respectively. Before each experiment, coal particle was glued at the tip a fine glass fiber with high-temperature inorganic glue. The glass fiber was mounted on the mechanism of a linear motor which could 


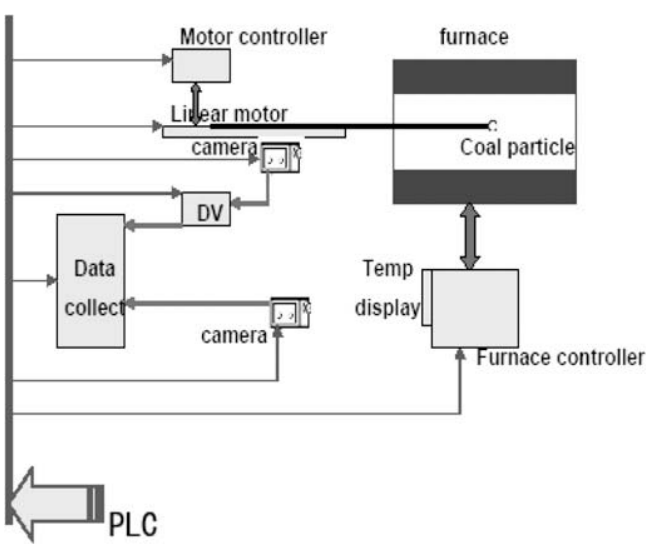

Fig. 1. Schematic of the experimental system.

Table 1

Tested coal composition

\begin{tabular}{|c|c|c|c|}
\hline & HLL & DTB & SDB \\
\hline \multicolumn{4}{|c|}{$\overline{\text { Ultimate (air dry) (\%) }}$} \\
\hline $\mathrm{C}$ & 54.12 & 56.59 & 72.54 \\
\hline $\mathrm{H}$ & 4.33 & 3.36 & 4.23 \\
\hline $\mathrm{N}$ & 1.22 & 1.12 & 1.17 \\
\hline $\mathrm{S}$ & 1.93 & 0.78 & 0.65 \\
\hline \multicolumn{4}{|c|}{ Proximate ( air dry) (\%) } \\
\hline Dry loss, $W_{\mathrm{ad}}$ & 13.1 & 3.1 & 6.3 \\
\hline Ash, $A_{\text {ad }}$ & 4.3 & 21.9 & 4.1 \\
\hline Vol. matter, $V_{\mathrm{ad}}$ & 38.1 & 31.3 & 29.1 \\
\hline Fixed C, FC & 44.5 & 43.7 & 60.5 \\
\hline
\end{tabular}

quickly translate the particle in and out of the furnace. Right before the drop, the particle was sent into the furnace to preheat for $1.0-1.5 \mathrm{~s}$ in order to make ignition surely happen at $\mu$-g. It was calibrated that the furnace heated the surface of the coal particles at a rate of $200-300 \mathrm{~K} / \mathrm{s}$ at the temperature of around $1123 \mathrm{~K}$, and no volatile content was found during the preheating period. The entire burning process of the particle was recorded with a color CCD camera, with a frequency of 25 frames/s.

Accurately measuring the surface temperature of the coal particle is important but difficult. To overcome the problems introduced by directly using thermocouples as discussed above, a nonintrusive method, i.e., RGB twin-color pyrometry method was developed.

The method was based on the theory that any color image of a radiative object can be regarded as the superposition of three single colors, red $(\mathrm{R})$, green $(\mathrm{G})$ and blue $(\mathrm{B})$ and thus the RGB values at a specific pixel of an image represent the radiative intensity at corresponding wavelength [15-17].

Given values of $R$ and $G$ were used, then,

$R=C_{r} * E_{\lambda_{\mathrm{R}}, T} \quad G=C_{g} * E_{\lambda_{g}, T}$
According to Wien's radiation law, at wavelength $\lambda$, the radiation intensity can be expressed as:

$$
E_{\lambda, T}=\varepsilon(\lambda) * \frac{C_{1}}{\lambda^{5}} \exp \left(-\frac{C_{2}}{\lambda T}\right)
$$

Thus,

$$
\begin{aligned}
& T=C_{2} *\left(\frac{1}{\lambda_{g}}-\frac{1}{\lambda_{r}}\right) / \ln \left(\frac{R}{G} * \frac{C_{g}}{C_{r}} * \frac{\varepsilon_{\lambda_{g}}}{\varepsilon_{\lambda_{r}}} * \frac{\lambda_{r}^{5}}{\lambda_{g}^{5}}\right) \\
& \ln (R / G)=C_{2} *\left(\frac{1}{\lambda_{g}}-\frac{1}{\lambda_{r}}\right) / T-\ln \left(\frac{C_{g}}{C_{r}} * \frac{\varepsilon_{\lambda_{g}}}{\varepsilon_{\lambda_{r}}} * \frac{\lambda_{r}}{\lambda_{g}}\right)
\end{aligned}
$$

In above equations, $E_{\lambda_{\mathrm{R}}, T}, E_{\lambda_{\mathrm{G}}, T}$ is the radiative intensity of at wavelength $\lambda_{\mathrm{R}}$ and $\lambda_{\mathrm{G}}, \mathrm{w} / \mathrm{m}^{3} ; C_{g}$ and $C_{r}$ are constants of the camera, and can be obtained by calibration with a black body furnace. $\varepsilon(\lambda)$ is the radiative emissivity at wavelength $\lambda ; T$ is temperature, in $\mathrm{K}$, and $C_{1}$ and $C_{2}$ are Planck constants.

Shown in Eq. (4), $1 / T$ varies linearly with the $\ln (R / G)$ term, and the slop can be determined by the calibration with a black body furnace. Therefore, by analyzing the RGB values of the images recorded by the color CCD camera, the temperature of specific pixels can be derived. It is worth to point out this method was only valid for obtaining the temperature before ignition. After ignition, the flame around the particle was too bright and the image color became saturated. This method is not valid in low temperature region neither as radiation was too weaker. The measurement error was estimated within $\pm 15 \mathrm{~K}$.

\section{Mathematic modeling}

Mathematically, a 1-D model considering the temperature variation inside the coal particle was developed. In the model, it was assumed that:

1. Pyrolysis occurred as the coal particle was heated up to a certain temperature, and the pyrolysis and devolatilization process could be described by Fu-Zhang model [14].

2. Coal particles were spherical and the release of their volatile matter was spherically uniform.

3. Ignition process was in quasi-steady states.

4. The inner particle temperature was not identical, while $\mathrm{Le}=1, \rho D=$ constant .

5. Surface reaction before ignition was: $\mathrm{C}+\mathrm{O}_{2}=\mathrm{CO}_{2}$.

6. The volatile content was $\mathrm{CH}_{4}$, and was oxidized into $\mathrm{CO}_{2}$ and $\mathrm{H}_{2} \mathrm{O}$ in one step.

7. Ideal gas assumption was valid.

8. No natural convection was included.

Along the radial temperature profile outside the particle, at a location $r$, if the temperature satisfied: $T_{r}>T_{r-\Delta r}$ and $T_{r}>T_{r+\Delta r}$, then ignition was defined as homogeneous. If before the 
homogeneous ignition, on the particle surface, $\frac{\mathrm{d}^{2} T_{p}}{\mathrm{~d} t^{2}}=0$ then ignition was defined as heterogeneous, based on the Somov thermal explosion theory (TET) [e.g.,[1-5]. More detailed introduction of the model can be found in Ref. [19].

\section{Results and discussion}

Figure 2 shows the selected images of the flames pictured at different time for DTB particles with $1.5 \mathrm{~mm}$ initial diameter burning at $\mu-\mathrm{g}$ and $1-$ $\mathrm{g}$, respectively. Similar to what was found in previous experiments [10], the flames are tulip-shaped at $1-\mathrm{g}$, and become spherical at $\mu-\mathrm{g}$. It can be also seen that flame is initially formed in the gaseous phase, namely homogeneously lit. In terms of flame shape and brightness, buoyancy effect is not very server in the beginning of ignition $(<600 \mathrm{~ms})$ as in the later period. In the beginning period, the quick evolution of volatile matter might over-whelm part of the buoyancy effect. Also, in this period temperature is low, and hereby the buoyancy effect is weak. With the depletion of volatile matter, temperature of burning gases becomes higher, and consequently buoyancy effect becomes more obvious. At the same time, the flame front moves towards the particle surface.

Figure 3 shows the modeling and $\mu$-g experimental results of temporal variation of the surface temperature of DTB coal particles with initial diameter of 1.5 and $2.0 \mathrm{~mm}$, respectively. The surface temperature increases with the residence time during ignition. The slope of temperature variation apparently increases at a certain time, and correspondingly homogeneous ignition starts. In this study, the ignition temperature is defined as the particle surface temperature when the gaseous volatile cloud around the particle is lit into a visual flame. It can be seen that the ignition temperatures obtained by the modeling agree the experimental data very well. And the ignition time at $1-\mathrm{g}$ is slightly longer than that at $\mu-\mathrm{g}$.

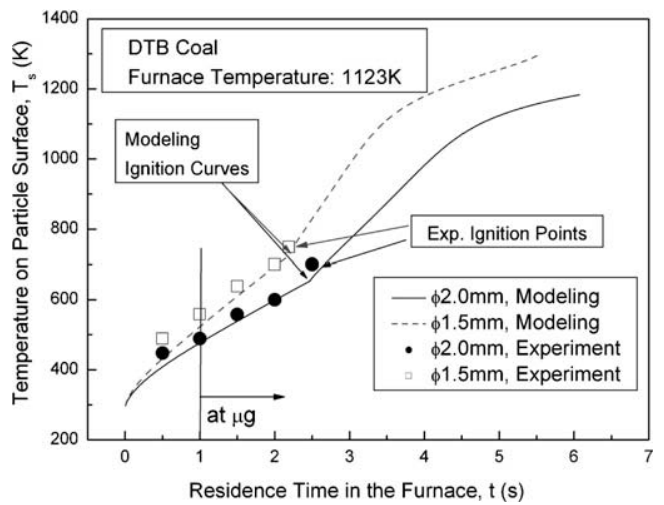

Fig. 3. Temporal variations of the surface temperature of coal particle for DTB coal with initial diameter of 1.5 and $2.0 \mathrm{~mm}$ during ignition.

Figure 4 shows the variation of ignition temperature with volatile content coal particles with $1.5 \mathrm{~mm}$ initial diameter burning at $\mu-\mathrm{g}$ and $1-\mathrm{g}$, respectively. It can be seen that at both $\mu-g$ and $1-g$, the ignition temperature decreases with the

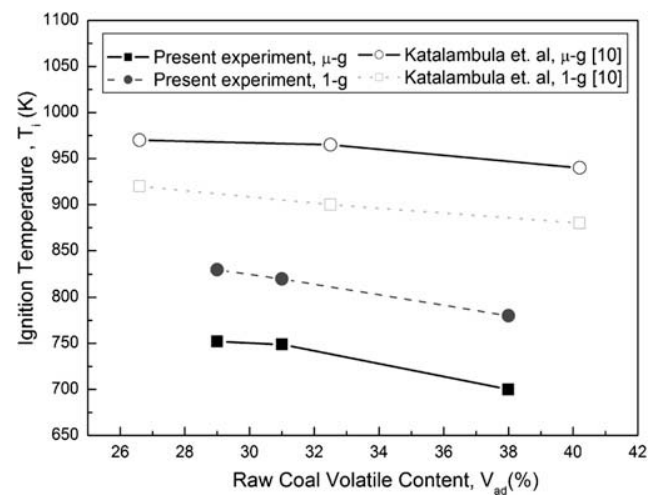

Fig. 4. Ignition temperatures for three coals with $1.5 \mathrm{~mm}$ initial diameter burning at $\mu-\mathrm{g}$ and $1-\mathrm{g}$.

\begin{tabular}{|c|c|c|c|c|c|c|c|c|}
\hline $\begin{array}{c}\text { Ign+, } \\
\text { ms }\end{array}$ & -5 & +5 & 200 & 400 & 600 & 800 & 1000 & 1200 \\
\hline$\mu-\mathrm{g}$ & & & & & & & & \\
\hline $1-g$ & & & & & & & & \\
\hline
\end{tabular}

Fig. 2. Selected images of flames at different time after ignition for DTB particles with $1.5 \mathrm{~mm}$ initial diameter burning at $\mu-\mathrm{g}$ and $1-\mathrm{g}$. 
increasing of volatile content of the coal. This trend agrees with that found by Katalambula et al. [10]. However, present experimental data show that for the same type of coal, the ignition temperature is lower at $\mu$-g than that at 1 -g. In previous experiments, as discussed before, the temperature was measured with the coiled thermocouples around the particle, and particles were heated by spot heater heating system. Thus, the initial environmental gas temperature was low, and the ignition reaction might happen at higher temperature. In addition, the spot heater would heat up the thermocouples and turn its reading to a higher-than-real value. The temperatures measurement in present study was by the nonintrusive method and the results sound more reasonable. At $\mu-\mathrm{g}$, the transport intensive is weaker than that at 1-g. Furthermore, the evolved volatile matter is accumulated around the particle rather than be swept away. Based on present results, it is suggested that at $\mu-\mathrm{g}$, the volatile acclamation effect prevails over the weakening of transport and thus lead an ignition temperature reduction. The reduction amplitude is about $50-80 \mathrm{~K}$, increasing slightly with volatile content.

Figure 5 shows the variation of ignition temperature with initial coal particle size for the three testing coals burning at $\mu-\mathrm{g}$ and $1-\mathrm{g}$, respectively. For all testing coals, the ignition temperature decreases when initial coal particle size increases from 1.5 to $2.0 \mathrm{~mm}$. The results confirmed the literatures ones obtained by various kinds of experimental methods and modeling [2-6,10], indicating that to reach the same volatile matter concentration for ignition, higher temperature is needed for smaller particles. Shown in Fig. 5, DTB and SDB have very close ignition temperature, mostly because they have close amount of volatile content. The HLL has lower ignition temperature due to its higher volatile content, consistent with the trend that ignition temperature

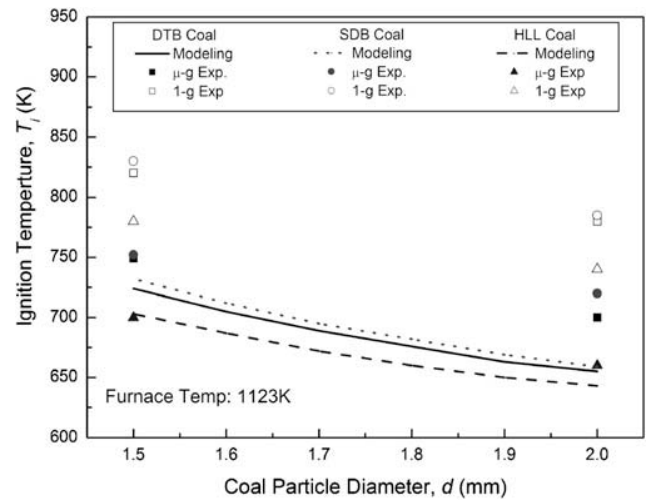

Fig. 5. Variation of ignition temperature with initial coal particle size for three testing coals burning at $\mu-\mathrm{g}$ and 1 -g.

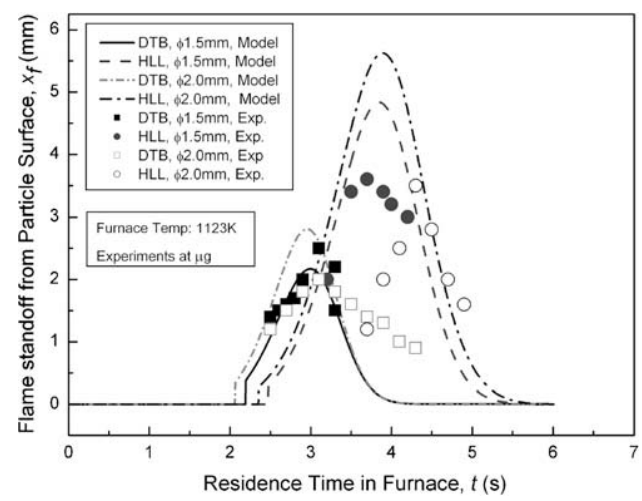

Fig. 6. Temporal variation of flame standoff from surface during the homogenous ignition for DTB and HLL coal particles with initial diameter of 1.5 and $2.0 \mathrm{~mm}$.

decreases with increasing volatile content $[10,14,18]$. Furthermore, the traditional modeling results are much closer to the experimental data obtained at $\mu-\mathrm{g}$ than the $1-\mathrm{g}$ ones, implying that the modeling in which the natural convection was neglected might introduce noticeable discrepancy when results are validated with the experimental data obtained at 1 -g.

Figure 6 compares the model prediction and $\mu$ $g$ experimental data of the temporal variation of flame standoff from particle surface during the homogenous ignition for DTB and HLL with initial diameter of 1.5 and $2.0 \mathrm{~mm}$, respectively. In the modeling, the location of flame front was defined as the place where temperature was of a maximum value, while in the experiments, it was defined at the pixel whose brightness was of a maximum value in image processing. Both the model prediction and $\mu$-g experimental data show that visual flame is initially formed closely around the particle surface, and then moves outward to a certain distance. As the volatile matter releases less and less, the flame moves inward to particle surface again. In addition, the maximum flame standoff increases as coal particle size increases. Shown in Fig. 6, the model predicts the variation trend well but with some discrepancy, especially for the $\Phi 2.0 \mathrm{~mm}$ coal particles. The discrepancy might mainly attributed to the simplification used in the model, e.g., the volatile content was assumed to be pure $\mathrm{CH}_{4}$ and the flame thickness was assumed to be infinitely thin, and the kinetic parameters selected. It might also introduced by some uncertainties of the experiments. More studies on the flame standoff variation are suggested.

Figure 7 compares the ignition temperature calculated different models with present experimental data. It can be seen that the predictions of present model agree well with the $\mu$-g experimental data. The ignition temperature of char 


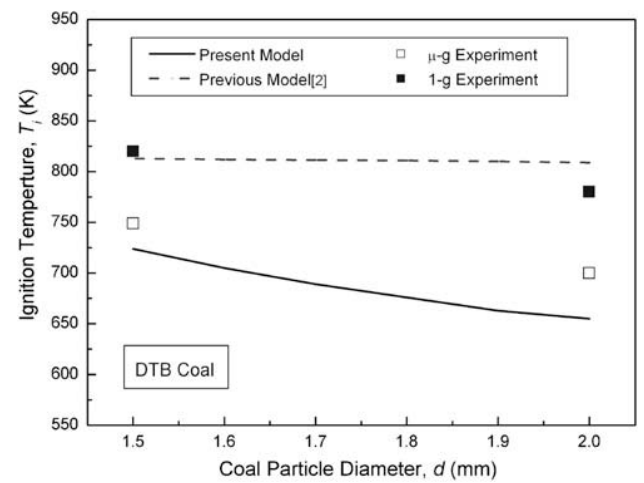

Fig. 7. Comparison of ignition temperature between predictions with different models and experimental data.

particles calculated by the general formula developed on TET and FZ index [13] is closer to that of coal particles of the same size obtained by experiments at 1-g, away from the corresponding $\mu$-g ones. Based on present results, the 1-g ignition temperatures of coal particles are higher than the $\mu$-g ones and coincidently close to that of char particles. The results indicate that some fundamentals of the traditional heterogeneous ignition theory need to be amended.

Figure 8 depicts the temperature distribution inside the particle at different time during the ignition process for DTB with initial particle size of $1.5 \mathrm{~mm}$. During the pyrolysis process and before ignition occurs, temperature inside the particles is noticeably non-uniform when thermal conduction is reckoned. The surface temperature can be as higher as nearly $150 \mathrm{~K}$ than the center one.

Figure 9 further shows the temporal variation of temperature difference between the surface temperature and center one during the entire ignition and combustion process. In the early pyrolysis duration before ignition, the difference is remark-

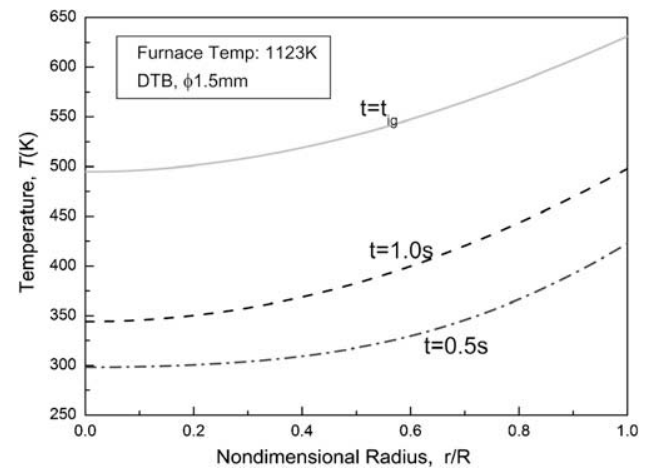

Fig. 8. The temperature distribution inside the coal particle calculated by the proposed model at different time before ignition.

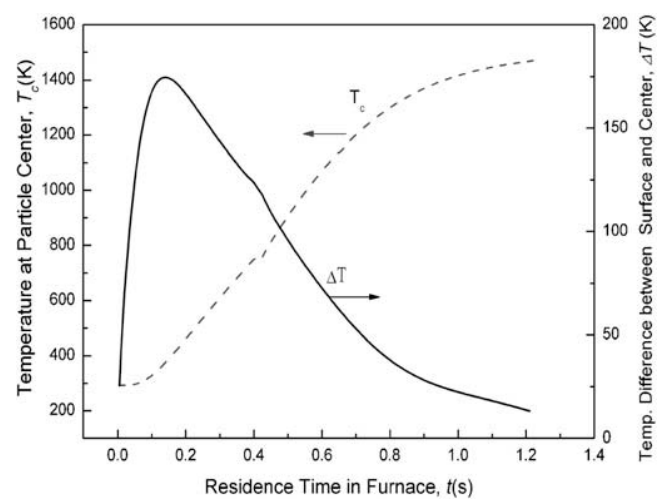

Fig. 9. Temporal variation of the temperature difference between surface and center of the coal particle during ignition and combustion process.

able, and then gradually decreases after ignition starts. The thermal conduction inside the coal particle introduces a lower average heating rate. The ignition of the coal particle is then postponed and the ignition temperature becomes higher.

In early studies [e.g.,1,2,4], the criterion for homogeneous ignition was applied to the particle surface, $\left.\frac{\partial T}{\partial r}\right|_{r=r}=0$. However, this might not be accurate since that homogeneous ignition occurred at the location away from the particle surface. Consequently, a new criterion defined as $\left.\frac{\partial T}{\partial r}\right|_{r=a}=0\left(a>r_{p}\right)$ was proposed by $\mathrm{Du}$ and Annamalai [5]. In this study, this criterion was adopted, coupled with the new model considering thermal conduction inside the coal particle. Calculated by present model, the critical particle diameter for ignition transient from heterogeneous to homogeneous is about $700 \mu \mathrm{m}$, against the value of $400 \mu \mathrm{m}$ with isothermal assumption, at ambient

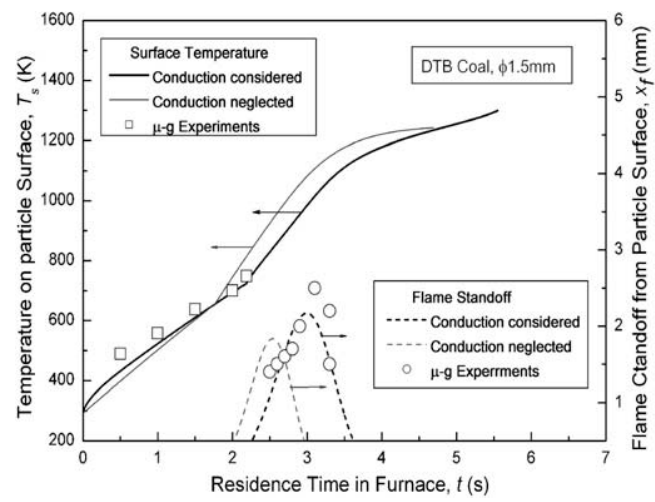

Fig. 10. Temporal variations of surface temperature and flame standoff during ignition for DTB coal particles with initial diameter $1.5 \mathrm{~mm}$ with and w/o consideration of inner thermal conduction. 
temperature $1500 \mathrm{~K}$ and oxygen concentration 0.23 .

Figure 10 shows the temporal variations of surface temperature and flame standoff during ignition for DTB coal particles of initial diameter of $1.5 \mathrm{~mm}$ with and without consideration of the inside temperature gradient, respectively. It can be seen that the results, of both particle temperature and flame standoff, calculated by the new model agree better with the $\mu$-g experimental data, indicating that thermal conduction inside the particle might not be neglected under certain conditions.

\section{Concluding remarks}

Coal ignition and combustion is a complicated process and some fundamental insights are still unveiled. At 1-g, the process might be greatly influenced by the natural convection, the buoyancy effect. The existing experimental data at $\mu-\mathrm{g}$ are rare and questionable. Lack of accurate experimental data, the ignitions models, in which no natural convection was considered, were often mis-validated with the experimental data obtained at $1-\mathrm{g}$.

In present study, some $\mu$-g and counterpart 1-g experiments were conducted on the ignition and combustion of three high volatile coals with initial diameter of 1.5 and $2.0 \mathrm{~mm}$, respectively. Experimental results show that the ignition and combustion of the coal particles was different at $\mu-\mathrm{g}$ from at $1-\mathrm{g}$, in flame shape, structure, brightness, and development, as well as the interaction between volatile release with the volatile-enclosed flames. At $\mu-\mathrm{g}$, part of volatile content was observed to release in a jet type. At the same time after ignition, flames were more spherical, thicker and laminated, and dimmer. In some cases, flames even become extinguished before the heterogeneous combustion occurs. Contradicted to the results reported in some previous studies, it was found that for a given coal and particle size, the ignition temperature was about $50-80 \mathrm{~K}$ lower at $\mu$-g than that at $1-\mathrm{g}$.

A mathematical model considering thermal conduction inside the coal particle was developed to describe the ignition process of single particles. The ignition criterion that the temperature gradient in the space away from the particle surface equaled to zero was adopted. With the proposed model, ignition temperature was slightly higher but closer to microgravity data. The model predictions also agreed in general with the $\mu$-g experimental results on flame standoff from coal particle surface. With the consideration of inner thermal conduction, the critical size for the phase transient from homogeneous to heterogeneous during coal ignition was estimated at about $700 \mu \mathrm{m}$ at ambient temperature $1500 \mathrm{~K}$ and oxygen concentration 0.23 .

\section{Acknowledgements}

The support and cooperation provided by NMLC are highly appreciated. This project was also supported by Natural Science Foundation of China (No. 50576041).

\section{References}

[1] R.H. Essenhigh, M.K. Misra, D.W. Shaw, Combust. Flame 77 (1989) 3-10.

[2] H. Karcz, W. Kordylewski, W. Rybak, Fuel 59 (11) (1980) 799-802.

[3] V.S. Gururajan, T.F. Wall, R.P. Gupta, J.S. Truelove, Combust. Flame 82 (2) (1990) 119-132.

[4] K. Annamalai, P. Durbetaki, Combust. Flame 29 (34) (1977) 193-208.

[5] X. Du, K. Annamalai, Combust. Flame 97 (1994) 339-436.

[6] D.K. Zhang, F.T. Wall, Fuel 73 (7) (1994) 1114 1119.

[7] P. Davini, P. Ghetti, L. Bonfanti, G. Michele, Fuel 75 (9) (1996) 1083-1088.

[8] J.C. Chen, M. Taniguchi, K. Narato, K. Ito, Combust. Flame 97 (1994) 107-114.

[9] H. Katalambula, K. Kitano, K. Ikeda, T.J. Chiba, Chem. Eng. Jpn. 29 (3) (1996) 523-530.

[10] H. Katalambula, J.I. Hayashi, T. Chiba, K. Ikeda, K.J. Kitano, Chem. Eng. Jpn. 30 (1) (1997) 146153.

[11] H. Katalambula, J.I. Hayashi, K. Kitano, T. Chiba, J. Chem. Eng. Jpn. 33 (1) (2000) 49-56.

[12] M. Gieras, R. Klemens, P. Wolanski, S. Wojcicki, Proc. Combust. Inst. 21 (1986) 315-323.

[13] C.I.M. Wendt, K. Ikeda, H. Katalambula, K. Kitano, C. Eigenbrod, H.J. Rath, Microgr. Sci. Technol. 12 (2) (1999) 51-55.

[14] W.B. Fu, Coal Combustion Theory and Macrogeneral Rules (in Chinese), Tsinghua University Press, 2003.

[15] C.Y. Wei, X.D. Li, Z.Y. Ma, et al., J. Combust. Sci. Technol. (in Chin.) 4 (3) (1998) 307-311.

[16] L. Chun, H.C. Zhou, P.F. Yu, Z.W. Jiang, Proc. Combust. Inst. 31 (2) (1997) 2771-2778.

[17] H.C. Zhou, Measurement Principles and Technologies of Flame Visualization in Furnaces (in Chinese), Science Press, Beijing, 2005.

[18] H.R. Yang, J.F. Lu, H. Zhang, G.X. Yue, Y.X. Guo, Fuel 84 (14-15) (2005) 1849-1853.

[19] M.M. Zhu, H. Zhang, Combust. Flame, 32 (2009) 2029-2035. 